association with their elders. Where now are the teachers and exemplars?

Theo. Gill.

PRICE OF THE REPORTS OF THE HARRIMAN EXPEDITION.

I DESIRE to correct an error in my review of volumes three and four of the Harriman Expedition, published in the preceding number of Science (May 2, 1904). As I have been informed, the price which I quoted from a trade-list of the publisher applies to volumes one and two of the series and not to subsequent volumes. The price of volumes three and four, the ones reviewed, is $\$ 5.00$ per volume.

Israel C. Russeil.

\section{SPECIAL ARTICLES.}

AN ENEMY OF THE COTTON BOLL WEETIL.

SPECIMENs of the cotton boll weevil were obtained in eastern Guatemala in 1902, during a visit made to that country in order to study the culture of coffee and rubber, for the United States Department of Agriculture. The insects, which were collected on the request of the Division of Entomology, were not found on the cotton cultivated by the Indians, but were very common in the flowers of the tree cotton growing spontaneously near a native house, a short distance from the cotton field. The beetles were secured in a rather inaccessible part of Alta Vera Paz, seldom visited by naturalists or other travelers. It lies between Cajapon and Sepacuite, and is inhabited only by primitive Indians and a very few Spanish-speaking 'natives' of mixed blood.

The Indian variety of cotton seemed very small and unpromising, only one or two bolls being borne on a plant; it seemed very strange also that so small a variety should be planted while the large tree cotton was so ready at hand. It was learned, however, from Mr. Kensett Champney, who has a most thorough acquaintance with the agricultural habits of the Indians, that this was the only variety of cotton planted by them in this district, and the one exclusively relied upon to furnish material for their native fibers. The absence of the weevils from the small Indian cotton was reported when the specimens of the beetles were brought back to Washington, but the diminutive size of the plant seemed to forbid any recommendation of profitable utility in the United States.

Later on, with the increasing acuteness of the boll weevil question and the voting of a special appropriation by Congress for the study of means of protection against its ravages, the existence of a variety of cotton in Guatemala which seemed not to be subject to the attacks of the boll weevil was recalled, and it seemed to the authorities of the Bureau of Plant Industry that every clue should be followed up. The Secretary of Agriculture authorized an investigation of the Indian cotton of Alta Vera Paz, to ascertain whether it possessed, in reality, any quality enabling it to resist the boll weevil, or to learn other causes of its immunity from the attacks of the insect. The custom of the Indians to plant their crops every year in tracts of land recently cleared by burning suggested an alternative possibility that if not actually resistant to the weevil the cotton might have an almost equally valuable tendency to quick growth, thus enabling a crop to be obtained before the weevils had time to become injuriously numerous. The importance of securing early varieties has been emphasized as the result of the investigations of the boll weevil in the United States.

In this part of Guatemala the present season has been much more rainy that that of 1902, and the cotton is much larger. Well grown plants bring to maturity from ten to twenty bolls of fair size, and even more. A thorough search shows that the weevil is present and able to injure the cotton, but reveals also an active enemy which keeps it in check. This is a large reddish brown ant which is attracted to the cotton by the food which it secures from three sets of extra-floral nectaries. Each leaf has a nectary on the under side of the midrib, from one to two centimeters from the base. Each of the large bracts of the involucre has a circular or broadly oval nectary close to the stem, and there is a third series of three nectaries at the base of the calyx, between the pair of small bracts alternating with the larger divisions of the involucre, of which 